\title{
Factors associated with enablement in general practice: cross-sectional study using routinely-collected data
}

\author{
Nicola Mead, Peter Bower and Martin Roland
}

\begin{abstract}
Background

Quality-improvement activities are most often focused on clinical quality indicators. However, patient evaluations are important additional indicators of the quality of general practice consultations, including measures of satisfaction or enablement (that is, the extent to which the consultation enhances the patient's feelings of confidence and ability to cope). There is limited evidence concerning factors associated with enablement in UK general practice.
\end{abstract}

Aim

To identify patient and practice characteristics associated with enablement scores following general practice consultations.

\section{Design of study}

Cross-sectional survey using a large routinely-collected dataset of patient evaluations of general practice (190 038 individual patient responses).

\section{Setting}

A total of 1031 UK general practices.

Method

Relationships between health, demographic factors, evaluations of general practice care, and patient selfreported enablement were estimated using multiple regression.

\section{Results}

The primary predictor of enablement was positive patient evaluation of the GPs' communication. Reported continuity of care accounted for a lower proportion of the variance. Of the included patient demographic variables, ethnicity was a key predictor, with patients from minority ethnic groups reporting greater enablement once other factors were controlled.

\section{Conclusion}

The current results provide support for the construct validity of the enablement measure. However, if enablement is to become a valid and useful measure of quality, it is necessary to understand the mechanisms by which enablement is increased in certain patients and practices. Detailed qualitative research may also be required to explain the relatively high scores of ethnic minority responders, despite lower overall satisfaction scores, and to understand why some items included in the enablement measure are regarded as 'not applicable' by a substantial minority of patients.

\section{Keywords}

enabling factors; general practice; methodology; patient satisfaction; quality of health care; survey.

\section{INTRODUCTION}

Improving the quality of primary health care requires suitable measures of quality. The 2004 general medical services (GMS) contract focuses predominantly on clinical indicators. It is therefore not comprehensive, ${ }^{1}$ largely ignoring the outcomes of consultations including health status, and patient evaluations such as satisfaction and enablement (that is, feelings of confidence, ability, and coping). It has been suggested that quality can be assessed additionally by measuring consultation length, continuity of care, and patient enablement, reflecting the core values of primary care. ${ }^{2}$ In this model, enablement is a measure of the outcome of consultations. This paper examines the enablement concept in more detail.

\section{Enablement}

The Patient Enablement Instrument (PEI) is a selfreport measure developed from literature reviews, supplemented with patient interviews. ${ }^{2-8}$ The items were designed to determine patients' feelings of confidence, ability, and coping following a consultation. ${ }^{9}$ The PEI comprises six items addressing patients' ability to understand and cope with their problem/illness after seeing the doctor, and the degree to which they feel able to cope with life, keep themselves healthy, feel confident about their

N Mead, PhD, research fellow; $\boldsymbol{P}$ Bower, $P h D$, reader; M Roland, DM, director, National Primary Care Research and Development Centre, University of Manchester, Manchester.

Address for correspondence

Dr Nicola Mead, University of Manchester, National Primary Care Research and Development Centre, 5th Floor, Williamson Building, Oxford Road, Manchester, M13 9PL. E-mail: nicki.mead@manchester.ac.uk

Submitted: 19 July 2007; Editor's response: 31 August 2007; final acceptance: 29 November 2007.

(c)British Journal of General Practice 2008; 58: 346-352.

DOI: 10.3399/bjgp08X280218 
health and help themselves. The original validation studies reported that longer consultations were associated with greater enablement. ${ }^{7}$

Determining the construct validity of a measure such as the PEI is crucial. Construct validity is concerned with understanding relationships between enablement and other theoretically relevant variables that may be input factors (for example, sociodemographic and clinical characteristics), process factors (for example, consultation length), or outcomes (for example, satisfaction and health status). Research to date suggests that older patients report significantly higher enablement, although they also receive significantly longer consultations. Men are significantly more enabled than women, despite women having longer consultations. There are also contradictory findings concerning patients whose first language is not English, in whom higher levels of enablement are achieved despite shorter consultations. ${ }^{8}$

Relationships with patients' health needs are inconsistent. Patients consulting with physical problems report higher levels of enablement than those with social and psychological problems, ${ }^{6}$ although a more recent study found enablement was not associated with case mix. ${ }^{8}$

In terms of process factors, enablement has been found to discriminate between short and long GP consultations, ${ }^{3}$ although this association is weaker for patients with psychological problems compared with those with physical or social problems. ${ }^{6}$ Enablement is correlated with patients' reports of how well they know the doctor, ${ }^{8}$ reduced by interruptions to the consultation, ${ }^{8}$ and associated with perceptions of the doctor's empathy ${ }^{10}$ and patient-centredness. ${ }^{11}$ Patients receiving immediate rather than delayed antibiotic prescriptions for lower respiratory tract infection also reported greater enablement. ${ }^{12}$

Finally, in terms of outcomes, one trial found that patients consulting nurse practitioners in primary care reported higher satisfaction but no greater enablement than those who saw a GP, ${ }^{13}$ supporting other evidence that the two constructs of enablement and satisfaction are distinct. ${ }^{7}$

Published research has begun to map the relationships between enablement and other variables, but if enablement is to develop as a useful measure of quality, it is necessary to examine these relationships further. This study uses a large-scale database of patients' assessments of primary care to determine:

- what health and demographic factors are associated with enablement; and

- how aspects of general practice care are associated with enablement.

\section{How this fits in}

Much work in quality improvement focuses on clinical quality indicators, but

enablement (that is, feelings of confidence, ability, and coping) may be a useful

patient-focused measure of the impact of general practice consultations.

However, there are limited data concerning what types of patients score highly

on enablement. Using routinely-collected data to examine predictors of

enablement in UK general practice, it was found that ratings of GP

communication and reported continuity of care were both associated with high

enablement scores. Patients in poorer health score lower, while ethnic minority

patients report higher levels of enablement once other factors are controlled.

More work is needed to understand the mechanisms by which enablement is

increased in certain patients and practices.

\section{METHOD}

\section{Dataset}

The 2004 GMS contract pays practices to assess patients' views of primary care using recommended surveys, one of which is the General Practice Assessment Questionnaire (GPAQ; www.gpaq.info/). Versions of the GPAQ are available for postal administration or completion after a GP consultation. GPAQ data from practices across the UK have been collected centrally by the National Primary Care Research and Development Centre at the University of Manchester.

The dataset used in the current analysis comprises 190038 individual patient responses to the postconsultation version of the GPAQ, collected across 1031 UK general practices during the 2005-2006 contract year.

The 32-item post-consultation version of the GPAQ is designed for self-completion by patients aged $\geq 16$ years, and contains 25 items evaluating access, continuity of care, GP communication skills, and enablement, plus seven health and sociodemographic items.

The main dependent variable in the present analysis (enablement) is described in more detail below. Key independent variables and their measurement are described in detail in Appendix 1.

\section{Patient enablement}

Enablement is measured in the GPAQ using three of the original six PEI items, namely the degree to which, having seen the doctor, patients feel able to: understand their problem(s)/illness; cope with the problem(s)/illness; and keep themselves healthy. This reduction in the number of items was to minimise burden and maximise response rates. The three items were selected in consultation with the PEI developers, and were regarded as having the greatest face validity and being least vulnerable to confounding. Data from previous studies using the 
PEI confirmed a high level of correlation between the three- and six-item measures $\left(r=0.95 ;{ }^{14} \mathrm{~J}\right.$ Howie, personal communication, 1991). Moreover, internal consistency is $0.92-0.93^{7,14}$ for the six-item PEI and 0.91 for the three-item scale.

Enablement items are scored on a three-point scale: 'much more than before the visit', 'A little more than before the visit', and 'The same as or less than before the visit' (scored 2, 1, and 0 respectively). A 'Does not apply' response option is provided, but is treated as missing for scoring purposes. An overall enablement scale score requires completion of at least two of the three items, and is calculated as a percentage of the maximum score across completed items.

\section{Data analysis}

The GPAQ dataset was collected via routine NHS sources as opposed to primary data collection. Use of such data raises concerns about the proportion of eligible patients who completed questionnaires, and the possibility of bias. Therefore, an initial analysis focused on assessing the representativeness of the sample through comparisons with the General Household Survey, ${ }^{15}$ which records NHS GP consultations by persons aged $\geq 16$ years in the 14 days preceding interview, by sex, age, and employment status.

SPSS version 11.5 was then used to undertake a hierarchical multiple regression with enablement score as the dependent variable. Cases with responses that were difficult to classify (for example, 'mixed' ethnic group or 'other' employment status: see Appendix 1 for details) and those with missing data on any of the included variables were omitted from the analysis. Factors associated with missing data were examined.

The main analysis initially examined the contribution of patient health and sociodemographic factors to enablement, then additional variables were added to examine the contribution of reported

Table 1. Characteristics of full GPAQ responder sample compared with General Household Survey (GHS) consulters.

\begin{tabular}{lcccccc} 
& \multicolumn{3}{c}{ Males $^{\mathrm{a}, \mathrm{c}}(\%)$} & \multicolumn{3}{c}{ Females $^{\mathrm{b}, \mathrm{d}}(\%)$} \\
\hline Age, years & $16-44$ & $45-64$ & $>65$ & $16-44$ & $45-64$ & $>65$ \\
\hline Working & 26 & 22 & 2 & 32 & 13 & 0 \\
GHS & 24 & 24 & 2 & 30 & 18 & 1 \\
GPAQ & 9 & 14 & 27 & 15 & 14 & 27 \\
\hline Unemployed/economically inactive & & & & & \\
GHS & 9 & 12 & 29 & 17 & 13 & 21 \\
\hline
\end{tabular}

GHS sample base: amales aged $\geq 16$ years who reported consulting a GP in previous 14 days ( $\mathrm{n}=2756$ ); ${ }^{\mathrm{b}}$ females aged $\geq 16$ years who reported consulting a GP in previous 14 days ( $n=4394)$. GPAQ sample base: ${ }^{c}$ male responders (aged $\geq 16$ years) to the post-consultation GPAQ survey ( $\mathrm{n}=65550$ ); ${ }^{\mathrm{d}}$ female responders (aged $\geq 16$ years) to the post-consultation GPAQ survey $(\mathrm{n}=118$ 442). GPAQ =General Practice Assessment Questionnaire. continuity of care and patients' overall ratings of GP communication. While no objective measure of consultation length is available, it should be noted that the GPAQ communication scale includes an item asking patients to rate the amount of time the doctor spent with them (Appendix 1).

\section{RESULTS}

\section{Representativeness}

Based on comparisons with the 2002 General Household Survey, women were somewhat overrepresented among GPAQ responders, and proportionately more women GPAQ responders were economically active. However, male responders were broadly similar in terms of age and employment status to males who reported consulting a GP in the General Household Survey (Table 1). The GPAQ sample was also representative of the total UK population in terms of ethnicity when compared with 2001 Census data.

Sixty-three per cent of the dataset was included in the regression analysis. Rates of missing data were less than $10 \%$ per variable for all variables except enablement, where a much higher proportion of cases had missing scores (23.8\%). Of those 45298 cases without enablement scores, 29926 (66\%) were not missing but had not been assigned an overall enablement score because they had marked more than one of the three items as 'Does not apply', and were thus excluded from the statistical analysis.

Descriptive data on patients included and excluded from the regression analysis are shown in Appendix 2. Compared to the 69500 patients with some missing data, those with complete data on all variables and included in the final regression model were more likely to be male (36.8\% versus $32.8 \%)$, and to report a longstanding illness (53.6\% versus $46.0 \%)$, or above-average consultation rates $(31.1 \%$ versus $24.8 \%$ ). Mean ratings of GP communication and enablement scores were very similar.

\section{Predictors of enablement}

Results of the regression modelling are shown in Table 2. Model A includes only the patient sociodemographic variables, model B additionally includes reported continuity of care, and model $\mathrm{C}$ includes sociodemographic factors, continuity of care, and communication, and represents the independent contribution of each variable to the prediction of enablement scores, controlling for all other included factors.

Patients reporting a longstanding illness and those with above-average rates of consulting in the past 12 months have lower enablement scores. Middleaged patients (31-60 years) are significantly less enabled than the reference group (aged 16-30 years). 
Table 2. Hierarchical regression $(95 \% \mathrm{Cl})$ of the contribution of $(\mathrm{A})$ sociodemographic and health factors, (B) continuity of care, and (C) ratings of GP communication, to overall \% enablement score $(n=120538)$.

\begin{tabular}{|c|c|c|c|}
\hline & Model A & Model B & Model C \\
\hline \multicolumn{4}{|l|}{ Chronic/longstanding illness } \\
\hline No & 0 & 0 & 0 \\
\hline Yes & $-6.8(-7.2$ to -6.3$)$ & $-7.4(-7.8$ to -6.9$)$ & $-7.7(-8.1$ to -7.3$)$ \\
\hline \multicolumn{4}{|l|}{ Number of GP consultations in past 12 months } \\
\hline Average or below & 0 & 0 & 0 \\
\hline Above average & $-1.6(-2.1$ to -1.2$)$ & $-2.3(-2.8$ to -1.9$)$ & $-4.0(-4.4$ to -3.6$)$ \\
\hline \multicolumn{4}{|l|}{ Age, years } \\
\hline $16-30$ & 0 & 0 & 0 \\
\hline $31-45$ & $-0.30(-0.95$ to 0.35$)$ & $-0.90(-1.5$ to -0.25$)$ & $-1.6(-2.2$ to -1.0$)$ \\
\hline $46-60$ & $-0.78(-1.6$ to 0.09$)$ & $-1.9(-2.7$ to -1.0$)$ & $-2.6(-3.3$ to -1.8$)$ \\
\hline $61-75$ & 3.2 (2.5 to 3.8$)$ & $1.4(0.73$ to 2.1$)$ & $-0.47(-1.1$ to 0.15$)$ \\
\hline$\geq 76$ & $4.6(3.6$ to 5.5$)$ & $2.4(1.4$ to 3.3$)$ & $0.23(-0.64$ to 1.1$)$ \\
\hline \multicolumn{4}{|l|}{ Sex } \\
\hline Male & 0 & 0 & 0 \\
\hline Female & $0.10(-0.32$ to 0.52$)$ & $0.04(-0.37$ to 0.46$)$ & $-0.77(-1.2$ to -0.38$)$ \\
\hline \multicolumn{4}{|l|}{ Socioeconomic status proxy } \\
\hline Rented/other arrangements & 0 & 0 & 0 \\
\hline Owner-occupier/mortgaged & $0.82(0.36$ to 1.3$)$ & $0.69(0.22$ to 1.1$)$ & $-0.32(-0.75$ to 0.11$)$ \\
\hline \multicolumn{4}{|l|}{ Ethnicity } \\
\hline White & 0 & 0 & 0 \\
\hline Black & $1.1(-0.42$ to 2.6$)$ & $1.4(-0.09$ to 2.9$)$ & 5.4 (4.0 to 6.8$)$ \\
\hline Asian & $0.65(-0.40$ to 1.7$)$ & $0.94(-0.09$ to 2.0$)$ & $6.1(5.1$ to 7.1$)$ \\
\hline Chinese & $-0.68(-4.4$ to 3.0$)$ & $0.50(-3.2$ to 4.2$)$ & 6.2 (2.8 to 9.6$)$ \\
\hline \multicolumn{4}{|l|}{ Employment status } \\
\hline Not employed/in full-time education & 0 & 0 & 0 \\
\hline Employed/in full-time education & $-0.56(-1.0$ to -0.09$)$ & $0.03(-0.44$ to 0.50$)$ & $0.05(-0.38$ to 0.48$)$ \\
\hline Reported continuity of care (6-point scale) & $\mathrm{n} / \mathrm{a}$ & $3.3(3.1$ to 3.5$)$ & $1.0(0.89$ to 1.2$)$ \\
\hline Communication \% score & $\mathrm{n} / \mathrm{a}$ & $\mathrm{n} / \mathrm{a}$ & $0.78(0.77$ to 0.79$)$ \\
\hline Constant & 67.7 & 77.6 & 10.1 \\
\hline $\mathrm{R}^{2}$ & 0.01 & 0.02 & 0.16 \\
\hline Change in $\mathrm{R}^{2}$ & 0.01 & 0.01 & 0.14 \\
\hline
\end{tabular}

Rank of significant independent predictors of enablement (model 3) in descending order of relative importance: (based on standardised $\beta$ coefficients): (1) positive patient evaluation of GP communication; (2) no chronic illness; (3) fewer GP consultations in past 12 months (versus above average); (4) greater reported continuity of care; (5) Asian/Asian British (versus white); (6) aged 16-30 years (versus 31-45 years); (7) black/black British (versus white); aged 16-30 years (versus 45-60 years); (8) male; (9)

Chinese (versus white).

However, the negative association with increasing age does not hold among older patients ( $\geq 61$ years). Females show a slight but significant reduction in enablement compared with males in the full model.

Patients in all three ethnic minority groups report lower levels of continuity of care and also evaluate GP communication skills more negatively than white patients (data not shown). However, in model C, white responders are significantly less enabled than ethnic minority patients. That is, when differences in communication and continuity are controlled for, ethnic minority patients report greater enablement. The magnitude of this effect is similar for black, Asian, and Chinese patients.

Patient-reported continuity and evaluations of GP communication are both significantly associated with enablement, with communication score showing the largest relative contribution in the full model.

\section{DISCUSSION}

\section{Summary of main findings}

A positive evaluation of communication skills is most strongly associated with enablement score, while continuity of care accounts for a lower proportion of the variance. Of patient demographic characteristics, minority ethnic group status was the most important factor predicting high enablement scores, with a magnitude of effect similar to that associated with not having a longstanding illness or disability. Enablement scores were not significantly related to economic variables such as home ownership.

\section{Strengths and limitations of the study}

The study has the advantage of a very large sample size, which means that estimates of relationships are relatively precise. However, as with any routinelycollected dataset, there are significant weaknesses. 
The exact denominator is not known, thus response rate cannot be calculated. However, comparison with data from other sources suggests that GPAQ responders are broadly representative of consulting patients in terms of age, sex, and ethnic mix. Nevertheless, there may be important biases associated with GPs selectively handing out questionnaires, and with non-response among patients given a survey. Although this could have affected the current estimate of mean enablement scores, it is much less likely to have affected the relationship between enablement and other items in the questionnaire, which is the main subject of this analysis.

The main analysis used multiple regression, which requires that cases have complete data on all variables. This led to the exclusion of approximately one-third of cases, the majority due to responders having checked more than one enablement item as 'not applicable'. Excluded cases were less likely to be males, report a long-term illness, or have a high consulting rate, all of which were associated with enablement scores (although not all in the same direction).

The analysis is cross-sectional and cannot determine cause; thus it is possible that patients who score high on enablement also communicate better with their GPs. A cross-sectional analysis can only examine reported effects for a single consultation, and thus cannot take into account previous consultations between patient and doctor. The unit of analysis is the individual patient, but enablement scores are clustered within doctors and within practices. Adjusting for clustering would increase the confidence intervals. However, the large sample size means that it is appropriate to focus on the actual size of the regression coefficient, rather than statistical significance alone.

Finally, the full model only explains around $16 \%$ of the variance in enablement scores. Other factors not included may be more important determinants (for example, the analysis does not include measures of perceived or reported accessibility of care).

\section{Comparison with existing literature}

Given that the key mechanism for improving patient outcome is likely to be the doctor-patient interaction, the finding that patients' rating of GP communication is the best predictor of enablement is not surprising and supports the construct validity of the enablement measure. In respect of continuity of care, some of the explanatory power of this variable is clearly accounted for by the fact that patients who report seeing their usual doctor more often also evaluate their GPs' communication skills more highly. However, independently of communication score and all other factors, a patient who sees their usual doctor 'always' will score 3\% higher on enablement than one who sees their usual GP 'some of the time'. Relationship continuity provides a more effective platform for delivering enabling care, over and above the benefits of good communication skills.

A key finding of the study is that patients in all three ethnic minority groups reported significantly greater enablement than white responders once communication ratings were controlled for. This is concordant with previous studies: Howie et al found that 'other language speaking patients' were more enabled despite having shorter consultations, ${ }^{8}$ and Denley et al also reported higher enablement among Pakistani and Indian responders. ${ }^{16}$ Ethnic differences could be explained by a number of potential mechanisms: actual differences in the quality or appropriateness of primary care delivery; variation in needs for primary care between or within population groups; or cultural differences between or within population groups in willingness to report favourable or unfavourable responses, or in their interpretation of the wording of enablement items.

The present analysis controls for need (associated with sociodemographic factors and self-reported long-term illness), and also for key aspects of service delivery (communication and continuity). This suggests that cultural differences in how the enablement items are interpreted may explain ethnic differences in scores, although it is possible that other factors not measured in the current study are important. For example, Mercer et al found that patients' expectations of health benefit resulting from consultations was a key determinant of enablement among individuals attending a homeopathic hospital. ${ }^{10}$ It could therefore be that ethnic minority patients expect to benefit more from consulting a GP than white patients do, which might explain the relatively high rates of consulting among minority ethnic groups reported by other studies. ${ }^{17,18}$

Patient health status is also an important independent predictor of enablement. Responders with a longstanding illness or disability score almost $8 \%$ lower on the enablement measure than those who do not. It has been suggested that there may be some relationship between enablement and the psychological concept of self-efficacy, ${ }^{19,20}$ which might account for this finding. Improving self-efficacy in patients with longstanding illness can be achieved through interventions such as the Expert Patients Programme. ${ }^{21}$ A key challenge is to achieve such benefits through routine general practice consultations. ${ }^{22}$

Patients in the middle age groups (31-45 years and 46-60 years) reported increasingly lower levels of enablement, but it is not clear why this trend does 
not continue in the oldest age groups. Evidence shows that older patients are consistently more positive about their health care, ${ }^{23-25}$ although whether this reflects real differences in care experiences, differences in expectations, or ways of responding to questionnaires is not known. The mechanism underlying the association between males and high enablement scores is also unclear, although it should be noted that the difference associated with sex is very modest and may not have clinical or policy significance.

\section{Implications for future research}

There is some evidence that satisfaction and enablement are only modestly related empirically, ${ }^{7}$ and there is a clear conceptual difference between patients' attitudes to the care they receive and reports of how that care assists them in dealing with their health problems. If the distinction between these concepts is valid, this raises the issue of their relative importance. Enablement and satisfaction are potentially important mediators of conventional outcomes, such as health-related quality of life, and their relative importance as predictors of quality of life deserves investigation. However, given the difficulties associated with relating general practice care to quality of life, it may be more important to determine the relative importance of satisfaction and enablement to patients. The authors are unaware of any empirical data to date concerning the relative worth attributed to these two outcomes.

An important issue concerns the applicability of enablement, given the relatively high proportion of responders who report that items do not apply. Although data on presenting problems are not collected by the GPAQ, it is possible that a significant proportion of these responses relate to consultations dominated by routine administrative tasks, such as repeat prescriptions and sickness certification. However, if patients report 'Does not apply' for other reasons, this may reflect on the validity and utility of the scale.

At present, practices are not paid on the basis of patients' satisfaction or enablement scores. If such payments were to be considered, or if data on patient evaluations were to be made publicly available, the issue of adjustment of enablement scores would become very important. One school of thought is that sociodemographic data, such as those presented here, should be used to adjust scores so that practices are not disadvantaged if their patient profile is associated with lower levels of enablement (for example, where there are relatively high rates of chronic illness). On the other hand, it may be argued that such adjustment is contrary to the spirit of quality improvement in the NHS, where practices should be encouraged to plan and deliver services to meet the specific needs of their patient populations, rather than artificially removing differences. As patients' evaluations of GP communication and reported continuity of care are key predictors of enablement, this adjustment may be inappropriate as enablement is at least theoretically under the control of practitioners.

The current results provide some additional support for the construct validity of the enablement measure. However for the measure to function well as an indicator of quality in UK primary care across the heterogeneous patient population, detailed qualitative research is needed to investigate reasons for the association between ethnic minority status and enablement score, and why some enablement items are regarded as 'not applicable' by a substantial proportion of patients.

\section{Funding body}

This work was conducted as part of the core research programme of the National Primary Care Research and Development Centre (NPCRDC), supported by the Department of Health. The views expressed are those of the authors and are not intended to represent the views of the NPCRDC or its funders

\section{Competing interests}

All three authors were involved in developing and validating the GPAQ questionnaire. The GPAQ is free to use for NHS staff, but commercial companies selling patient evaluation services are required to pay a licence fee. Funds derived from selling the GPAQ in these instances are received by the NPCRDC and used to support GPAQ administration and research activities. No individual gains directly from the use of the GPAQ

\section{Acknowledgements}

We would like to thank the patients who completed questionnaires, and those GPAQ service suppliers, primary care trusts, and individual practices that provided the NPCRDC with their data.

\section{Discuss this article}

Contribute and read comments about this article on the Discussion Forum: http://www.rcgp.org.uk/bjgp-discuss

\section{REFERENCES}

1. Campbell S, Roland M, Buetow S. Defining quality of care. Soc Sci Med 2000; 51(11): 1611-1625.

2. Howie J, Heaney D, Maxwell M, et al. Developing a 'consultation quality index' (CQI) for use in general practice. Fam Pract 2000; 17(6): 455-461.

3. Howie J, Porter M, Heaney D, Hopton J. Long to short consultation ratio: a proxy measure of quality of care for general practice. $\mathrm{Br} J \mathrm{Gen}$ Pract 1991; 41(343): 48-54.

4. Howie J, Heaney D, Maxwell M. Care of patients with selected health problems in fundholding practices in Scotland in 1990 and 1992: needs, process and outcome. Br J Gen Pract 1995; 45(392): 121-126.

5. Howie J, Heaney D, Maxwell M. General practice fundholding: shadow project — an evaluation. Edinburgh: University of Edinburgh, 1995.

6. Howie J, Heaney D, Maxwell M. Measuring quality in general practice. Occasional paper series, 75. London: The Royal College of General Practitioners, 1997.

7. Howie J, Heaney D, Maxwell M, Walker J. A comparison of Patient Enablement Instrument (PEI) against two established satisfaction scales as an outcome measure of primary care consultations. Fam Pract 1998; 15(2): 165-171.

8. Howie J, Heaney D, Maxwell M, et al. Quality at general practice consultations: cross sectional survey. BMJ 1999; 319(7212): 738-743.

9. Porter M. The development of process and outcome measures for 
general practice consultations. In: Howie J, Heaney D, Maxwell M (eds). Measuring quality in general practice. London: Royal College of General Practitioners, 1997; 31-32.

10. Mercer S, Reilly D, Watt G. The importance of empathy in the enablement of patients attending the Glasgow Homeopathic Hospital. Br J Gen Pract 2002; 52(484): 901-905.

11. Little $\mathrm{P}$, Everitt $\mathrm{H}$, Williamson I, et al. Observational study of the effect of patient centredness and positive approach on outcomes of general practice consultations. BMJ 2001; 323(7318): 908-911.

12. Dowell J, Pitkethly M, Bain J, Martin S. A randomised controlled trial of delayed antibiotic prescribing as a strategy for managing uncomplicated respiratory tract infection in primary care. $\mathrm{Br} J \mathrm{Gen}$ Pract 2001; 51(464): 200-205.

13. Venning P, Durie A, Roland M, et al. Randomised controlled trial comparing cost effectiveness of general practitioners and nurse practitioners in primary care. $B M J 2000 ; 320$ (7241): 1048-1053.

14. Mead N. Patient-centredness in general practice consultations: theory, measurement and relationships with outcomes. $\mathrm{PhD}$ thesis. Manchester: University of Manchester, 2002.

15. Rickards L, Fox K, Roberts C, et al. Living in Britain: results from the 2002 General Household Survey. London: The Stationery Office, 2004.

16. Denley J, Rao J, Stewart A. How do patients rate the quality of consultations in primary care? A patient enablement survey from practices within a primary care trust in Sandwell. Quality in Primary Care 2003; 11(3): 181-187.
17. Smaje C, Le Grand J. Ethnicity, equity and the use of health services in the British NHS. Soc Sci Med 1997; 45: 485-496.

18. Baker D, Mead N, Campbell S. Inequalities in morbidity and consulting behaviour for socially vulnerable groups. $\mathrm{Br} \mathrm{J} \mathrm{Gen} \mathrm{Pract}$ 2002; 52(475): 124-130.

19. Mead N, Bower P, Hann M. The impact of general practitioners' patient-centredness on patients' post-consultation satisfaction and enablement. Soc Sci Med 2002; 55(2): 283-299.

20. Bandura A. Self efficacy: towards a unifying theory of behavioural change. Psychol Rev 1977; 84(2): 191-215.

21. Kennedy A, Reeves D, Bower P, et al. The effectiveness and cost effectiveness of a national lay-led self-care support programme for patients with long-term conditions: a pragmatic randomised controlled trial. J Epidemiol Community Health 2007; 61(3): 254-261.

22. Blakeman $\mathrm{T}$, MacDonald $\mathrm{W}$, Bower $\mathrm{P}$, et al. A qualitative study of GPs' attitudes to self-management of chronic disease. Br J Gen Pract 2006; 56(527): 407-414.

23. Hall J, Dornan M. What patients like about their medical care and how often they are asked: a meta analysis of the satisfaction literature. Soc Sci Med 1988; 27(9): 935-939.

24. Williams S, Calnan M. Key determinants of consumer satisfaction with general practice. Fam Pract 1991; 8(3): 237-242.

25. Lewis JR. Patient views on quality care in general practice: literature review. Soc Sci Med 1994; 39(5): 655-670. 


\section{Appendix 1. Independent variables in the analysis and their measurement.}

\begin{tabular}{|c|c|c|}
\hline Variable & Measurement & Notes \\
\hline \multicolumn{3}{|l|}{ Demographic } \\
\hline Age & $\begin{array}{l}\text { Five categories: ' } 16-30 \text { ', ' } 31-45 \text { ', } \\
\text { ' } 46-60 \text { ', ' } 61-75 \text { ', and ' } 76+\text { years' }\end{array}$ & ' $16-30$ ' years is the reference category \\
\hline Sex & Two categories: 'Male', 'Female' & 'Male' is the reference category \\
\hline Ethnicity & $\begin{array}{l}\text { Four categories: 'white', 'Asian/Asian British', } \\
\text { 'black/black British', and 'Chinese' }\end{array}$ & $\begin{array}{l}\text { Two other response categories ('Mixed' and 'Other } \\
\text { ethnic group') were excluded. 'White' is the reference } \\
\text { category }\end{array}$ \\
\hline Employment status & $\begin{array}{l}\text { Originally seven categories recoded as two: } \\
\text { 'Employed/in full-time education' or 'Not' } \\
\text { (including 'Unemployed', 'Unable to work due } \\
\text { to long-term sickness', 'Looking after home/ } \\
\text { family', or 'Retired from paid work') }\end{array}$ & $\begin{array}{l}\text { 'Other' employment status was excluded. 'Not employed/ } \\
\text { in full-time education' is the reference category }\end{array}$ \\
\hline Accommodation status & $\begin{array}{l}\text { Two categories: } \\
\text { 'Owner-occupied/mortgaged' } \\
\text { or 'Rented/other arrangements' }\end{array}$ & $\begin{array}{l}\text { Included as proxy for socioeconomic status. } \\
\text { 'Rented/other arrangements' is the reference category }\end{array}$ \\
\hline \multicolumn{3}{|l|}{ Health-related } \\
\hline $\begin{array}{l}\text { Longstanding illness } \\
\text { or disability }\end{array}$ & $\begin{array}{l}\text { Two categories: 'Yes' (presence), } \\
\text { 'No' (absence) }\end{array}$ & 'Absence' is the reference category \\
\hline $\begin{array}{l}\text { Number of GP consultations } \\
\text { in past } 12 \text { months }\end{array}$ & $\begin{array}{l}\text { Originally five categories recoded as two: } \\
\text { 'Average or below' and 'Above average' }\end{array}$ & $\begin{array}{l}\text { Average number of consultations is four for men, six for } \\
\text { women. }{ }^{15} \text { 'Average or below' is the reference category }\end{array}$ \\
\hline \multicolumn{3}{|l|}{ Healthcare delivery } \\
\hline Continuity of care & $\begin{array}{l}\text { 'In general, how often do you see your } \\
\text { usual doctor?' measured on a 6-point scale } \\
\text { from 'Always' to 'Never' item. }\end{array}$ & $\begin{array}{l}\text { GPAQ measures continuity of care using a two-part } \\
\text { 'report and evaluate' item. For this analysis, only the } \\
\text { report item was used as responses are less likely to be } \\
\text { confounded }^{\text {a }}\end{array}$ \\
\hline $\begin{array}{l}\text { GP communication in } \\
\text { the consultation }\end{array}$ & $\begin{array}{l}\text { Eight-item evaluative measure of GP } \\
\text { communication skills with patient (that is, } \\
\text { history taking, listening, putting at ease during } \\
\text { examination, involving in decisions, explaining, } \\
\text { length of consultation, patience caring, and } \\
\text { concern). Each item measured on a six-point } \\
\text { scale ('Very poor' to 'Excellent') }\end{array}$ & $\begin{array}{l}\text { Calculated as a percentage of the maximum achievable } \\
\text { score across completed items (minimum of four } \\
\text { completed items required for scoring) }\end{array}$ \\
\hline
\end{tabular}

${ }^{a}$ Patients who do not have a usual doctor (or one they feel they know best at the practice) miss this item and are therefore excluded from the analysis. $\mathrm{GPAQ}=$ General Practice Assessment Questionnaire. 


\section{Appendix 2. Characteristics of patients included and excluded from the regression analysis.}

\begin{tabular}{|c|c|c|c|}
\hline & $\begin{array}{c}\text { Regression sample } \\
\quad(n=120538)\end{array}$ & $\begin{array}{l}\text { Cases excluded from } \\
\text { regression sample }^{\mathrm{a}}\end{array}$ & $\begin{array}{c}\text { Excluded cases with missing } \\
\text { enablement score }\end{array}$ \\
\hline \multicolumn{4}{|l|}{ Longstanding illness/disability } \\
\hline Yes, \% & 53.6 & $46.0(n=63367)$ & $46.8(n=43292)$ \\
\hline \multicolumn{4}{|c|}{ Number of GP consultations in past 12 months } \\
\hline Above average, \% & 31.1 & $24.8(n=67025)$ & $25.1(n=44528)$ \\
\hline Mean age in years $(95 \% \mathrm{Cl})$ & $50.7(50.6$ to 50.8$)$ & 49.6 (49.5 to 49.8$)(n=69500)$ & $50.2(50.0$ to 50.3$)(n=45298)$ \\
\hline $16-30$ & 15.1 & 19.2 & 17.5 \\
\hline $31-45$ & 26.5 & 26.1 & 26.7 \\
\hline $46-60$ & 8.4 & 7.1 & 7.2 \\
\hline $61-75$ & 41.2 & 37.4 & 38.5 \\
\hline$\geq 76$ & 8.8 & $10.2(n=69500)$ & $10.1(n=45298)$ \\
\hline Female, \% & 63.2 & $67.2(n=69007)$ & $68.5(n=45153)$ \\
\hline \multicolumn{4}{|l|}{ Socioeconomic status proxy } \\
\hline \multicolumn{4}{|l|}{ Ethnicity, \% } \\
\hline White & 94.3 & 93.9 & 94.8 \\
\hline Black & 1.7 & 2.0 & 1.7 \\
\hline Asian & 3.7 & 3.9 & 3.3 \\
\hline Chinese & 0.3 & $0.3(n=63811)$ & $0.2(n=43807)$ \\
\hline \multicolumn{4}{|l|}{ Employment status } \\
\hline Employed/in full-time education, \% & 51.9 & $53.8(n=63901)$ & $52.8(n=43689)$ \\
\hline \multicolumn{4}{|l|}{ Patient-reported continuity of care, \% } \\
\hline Always & 20.0 & 21.3 & 21.2 \\
\hline Almost always & 37.5 & 36.0 & 36.8 \\
\hline A lot of the time & 16.9 & 16.2 & 15.8 \\
\hline Some of the time & 19.6 & 19.9 & 19.3 \\
\hline Almost never & 5.0 & 5.4 & 5.7 \\
\hline Never & 0.9 & $1.1(n=53345)$ & $1.2(n=39409)$ \\
\hline
\end{tabular}

Patient evaluation of GP communication,

mean \% score $(95 \% \mathrm{Cl})$

83.0 (82.9 to 83.1$)$

81.5 (81.3 to 81.6$)(n=62239)$

$82.0(81.8$ to 82.2$)(n=38593)$

Enablement score,

mean \% score $(95 \% \mathrm{Cl})$

65.5 (65.3 to 65.7$)$

65.0 (64.6 to 65.5$)(n=24202)$

$\mathrm{n} / \mathrm{a}$

${ }^{a}$ A total of 69500 cases were excluded due to missing data on one or more variables in the analysis. Data presented correspond to the valid percentage of this sample with the stated characteristic (that is, denominator excludes those with missing data on that particular variable). ${ }^{\mathrm{b}}$ Of excluded cases, 45298 (65\%) had no enablement score. Data presented correspond to the valid percentage of this sample with the stated characteristic (that is, denominator excludes cases with missing data on that particular variable). 